\title{
Studies on cauliflower leaves powder and its waste utilization in traditional product
}

Shivani A. Pankar and Deepak T. Bornare

Received : 10.04.2018; Accepted : 13.04.2018

See end of the Paper for authors' affiliation

Correspondence to :

Shivani A. Pankar Department of Agricultural Engineering, Maharasthra Institute of Technology, Aurangabad (M.S.) India Email : shivanipankar1111@ gmail.com
- Abstract : This review aim is to studied on cauliflower leaves powder.Cauliflower is one of the most common and popular vegetable grown in India.The family of cauliflower leaves is Brassicaceae. Cauliflower leaves rich source of $\beta$ carotene, iron and calcium but it has higher waste index. Cauliflower leaves are also come in waste products category and thus can be utilized in value added products for treat anemia disease and those people who suffering from micronutrients deficiency. This review studied on the nutritional composition of cauliflower leaves powder and its utilization into traditional product. There is number of different drying methods tray drying, microwave oven drying and sun drying method areuse for drying of cauliflower leaves at different temperature for specific time. After drying it can be store for use during lean season. These vegetables are also rich in beneficial plant's metabolites, which include sulfur containing glucosinolates, anthocyanin's, flavonoids, trepans, S-methyleysteine sulfoxide, and other compound to improve the nutritional, physico-chemical and sensory quality and very beneficial to health. Phytochemicals of cauliflower leaves are stronger antioxidants and are thought to reduce the risk of chronic diseases by protecting against free radical damage.

- Key words : Cauliflower leaves, $\beta$ carotene, Iron, Phyto-chemicals, Drying method

- How to cite this paper : Pankar, Shivani A. and Bornare, Deepak T. (2018). Studies on cauliflower leaves powder and its waste utilization in traditional product. Internat. J. Agric. Engg., 11(Sp. Issue) : 95-98, DOI: 10.15740/HAS/IJAE/11.Sp. Issue/95-98. 